\title{
Analysis and Performance of Saturated Three-Phase Wound Rotor Induction Machine
}

\author{
Osama Yaseen M. Al-Rawi, MSc, PhD, MIEEE \\ Dean of College of Engineering, Electrical and Electronics Engineering Department, College of Engineering,
}

Gulf University, Sanad, Kingdom of Bahrain

\begin{abstract}
This paper deals with special problem occurs with Induction Machine (IM) which is the saturation problem. Magnetic saturation is accounted by the nonlinear magnetizing curve of the iron core. Two machines of wound-rotor three-phase Induction Machine were used to make a comparison for different situations. The first machine running without saturation condition whiles the other running under saturation condition. Most of the students and researchers were considering the ideal case of IM in their researches. However it is better to study the impact of saturation on the machine when using the IM in different applications. This gives the research a stronger analysis and conclusion, and at the end of the day the results will be fruitful for the researcher. It is also necessary for the researcher to be familiar with the practical problems that occurs in the factories.
\end{abstract}

Keywords: Induction Machine, Analysis, Performance, saturation problem, and MATLAB/Simulink.

\section{INTRODUCTION}

This paper describes the analysis and characteristics of the induction machines working under the impact of saturation; this can be achieved by initiating a comparison between two machines working under different situations. Based on this basis we can use the facilities of Matlab/Simulink to build the proposed system to study the simulation results obtained in this paper. However there are a lot of problems and faults that occurs in factories when using the IM without finding a logical reason. One of these important problems could be the IM saturation problem which is occurs in the machines during work. Here comes the role of analysing and studying of the situation of saturation of the machine and then we can find out the real reasons and to identify appropriate solutions. So the ideal case study of the machine is not enough during research, especially when we talk about the practical side of the projects then there will be a lot of problems that are difficult to be detected and analysed. Therefore the researchers would have a comprehensive nature by including the saturation problem in there researches. There are many basic concepts that must be confirmed before starting the analysis of electrical machines. The principle of electromagnetic energy conversion is perhaps the fundamental of machine analysis. The main principles that must be achieved are (1) the derivation of equivalent circuit of the magnetic couple circuits, (2) the idea of a sinusoidally distributed winding, (3) the concept of a rotating air-gap magnetomotive force (MMF), and (4) the derivation of winding inductances.

Yuefeng Liao, and Thomas A. Lipo [1] proposed the behaviour of the saturation third harmonic and how energy is converted from fundamental to third harmonic form in a squirrel-cage induction machine in the presence of magnetic saturation. Charles R. Sullvian, and Seth R. Sanders [2] they proposed new nonlinear $\pi$ model for an induction machine operating in magnetic saturation. It is based on a magnetic circuit model of a rotor-stator both pair with nonlinear reluctance elements representing the saturation in the rotor and in the stator. Asmo Tenhunen et al [3] they studied the effects of magnetic saturation on the radial magnetic force in induction machines when the rotor is performing cylindrical circular whirling motion. Impulse method in the finite element analysis is used to calculate the forces and the eccentricity harmonics from both, the air gap flux density and rotor currents. T. Matsusaka et al [4] proposed the magnetic field analysis method of an induction motor using three-dimensional axisymmetric finite element method. Darizon A. de Andrade et al [5] they studied the effects of magnetic saturation on the operation of induction motors driven by static converters are analyzed. A mathematical model based on magnetic harmonic functions is used to account for saturation. Distortions on the air gap flux due to nonlinear magnetic characteristics lead to appearance of space harmonics in the resultant flux density distribution. D. Dolinar et al [6] proposed the tracking control design of an induction motor, based on input-output linearization with magnetic saturation included. Magnetic saturation is accounted for by the nonlinear magnetizing curve of the iron core and is used in the control design, the observer of state variables, and in the load torque estimator. J. Faiz and B. M. Ebrahimi [7] presented a no-load induction motor under static eccentricity is modeled using time stepping finite element method; current, torque, and speed signals of the motor are obtained by finite element method and used for static eccentricity fault diagnosis and analysis. F. Oliveira et al [8] studied the effects of running an electric motor near and in the saturation zone of the electromagnetic hysteresis curve, namely mechanical effects such as mechanical vibrations and rotation speed apart from the classic electrical and thermal effects. J. P. Lecointe et al [9] focused on the noise and vibrations of 3speed 3-phase induction motors. They proposed an analytical method to distinguish the phenomenon 
responsible on the magnetic noise, especially the toothing conditions, the wound rotor is short-circuited on itself just and the saturation. Ahmed Nasser B and Mohammed like the squirrel-case rotor.

Fawaz [10] they suggested an improved equivalent circuit model is proposed that accounts not only the saturation effects in the stator and rotor, but also independently, for saturation in both the rotor and stator cores. The theory of reference frame has been effectively used as an efficient approach to analyze the performance of an IM by using Matlab/Simulink. Lakhya Jyoti Phukon and Neelanjana Baruah [11] presented a step by step Simulink implementation of an induction machine using dq0 axis transformations of the stator and rotor variables in the arbitrary reference frame. The first important formulas are stated and then according to these formulas a generalized model of a three phase induction motor is developed and implemented.

\section{WOUND ROTOR INDUCTION MOTOR}

To start the motor, the resistance of the wye-connected (external star connected rheostat) shown in Fig.1 speed controller is inserted in the rotor circuit. The stator circuit's energized from the three-phase line. The voltage induced in the rotor develops currents in the rotor circuit. The rotor currents, however, are limited in value by the resistance of the speed controller. As a result, the stator current also is limited in value. In other words, to minimize the starting surge of current to a wound-rotor induction motor, insert the full resistance of the speed controller in the rotor circuit. The starting torque is affected by the resistance inserted in the rotor secondary. With resistance in the secondary, the power factor of the rotor is high or close to unity. This means that the rotor current is nearly in phase with the rotor-induced voltage. If the rotor current is in phase with the rotor-induced voltage, then the rotor magnetic poles are being produced at the same time as the stator poles. This creates a strong magnetic effect, which creates a strong starting torque. As the motor accelerates, steps of resistance in the wye-connected speed controller can be cut out of the rotor circuit until the motor accelerates to its rated speed.

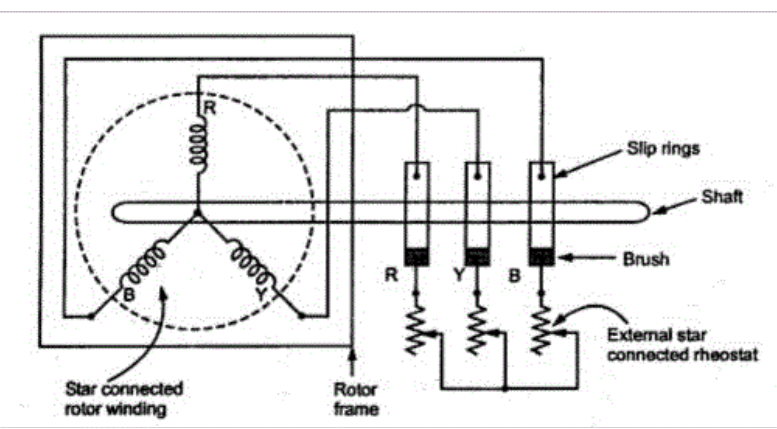

Fig. 1 star connected rotor winding with external star connected rheostat

When running under normal conditions, the slip-rings arc automatically short-circuited by means of a metal collar, which is pushed along the shaft and connects all the rings together. Next, the brushes are automatically lifted from the slip-rings to reduce the frictional losses and the wear and tear. Hence, it is seen that under normal running

A. Advantages

The advantages of slip ring induction motor are:

- It has high starting torque and low starting current.

- Possibility of adding additional resistance to control speed

\section{B. Disadvantages}

The disadvantages of slip ring induction motor:

- Initial and maintenance cost is more compared to squirrel cage motor because presence of slip rings, brushes, short circuiting devices etc.

- Speed regulation is poor when operated with external resistances in rotor circuit

- Efficiency and power factor of slip ring motor is lower compared to squirrel cage induction motor

- Lower power factor at the light loads

- Sensitivity to fluctuations in supply voltage

\section{III.THE MAGNETIC SYSTEM}

If saturation is neglected, the system is considered as a linear. When the magnetic system is linear, the flux linkages are generally expressed in terms of inductances and currents [1]. The analysis of electric machine is generally performed assuming a linear magnetic system. Sometimes a saturation problem occurs during machine operation, heating of the magnetic material exists due to hysteresis losses. Unfortunately most of the students and researchers take the simple way in their research by considering the machine as a linear magnetic system without studying the effect of the saturation through the researches. Also, for a practical side most of the designers do the same [11]. The magnetization characteristics of the machine materials are given in the form of the magnitude of the flux density versus magnitude of field strength (B-H curve) as shown in Fig. 2

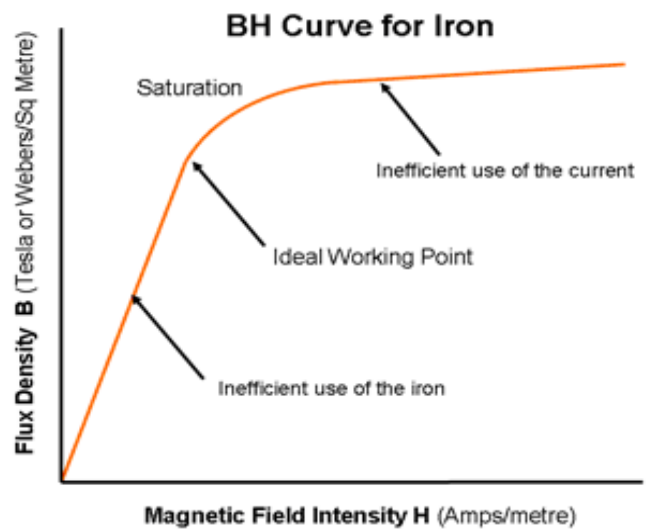

Fig. 2 The magnetization characteristics of the machine (B-H curve)

\section{IV.SIMULATION RESULTS}

The computer simulation results are presented in this section by using MATLAB/SIMULINK version 2013b. However it is assumed that the two machines are identical 
and its parameters are illustrated in Fig. $3 \& 4$ below. through the circuit but there is a limit to the flux density However the two machines are working in two different which can be created in magnetic materials such as iron conditions; the first machine working under unsaturated when the material is said to be saturated. Above this point condition with a certain parameters shown in Fig. 3, while more and more MMF is needed to create less and less flux. the second machine working under saturated condition In other words the reluctance increases sharply when the with parameters shown in Fig. 4 by activated the material saturates. For maximum efficiency, electric simulation saturation condition. The overall SIMULINK block diagram of the system is illustrated in Fig 5.

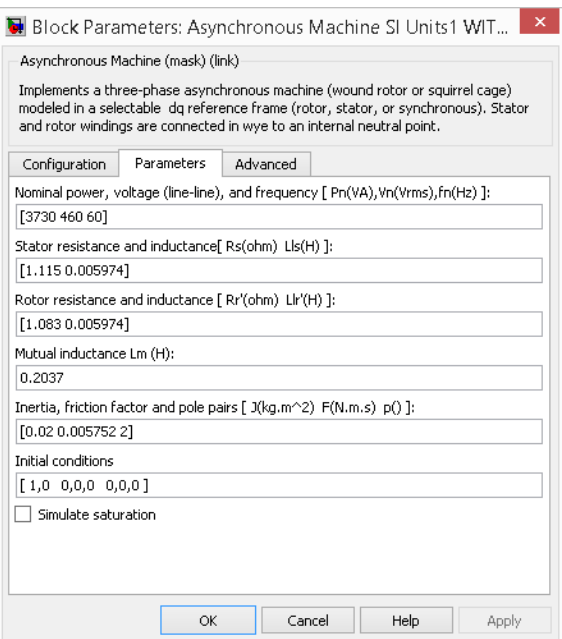

Fig. 3 Block parameters of unsaturated IM

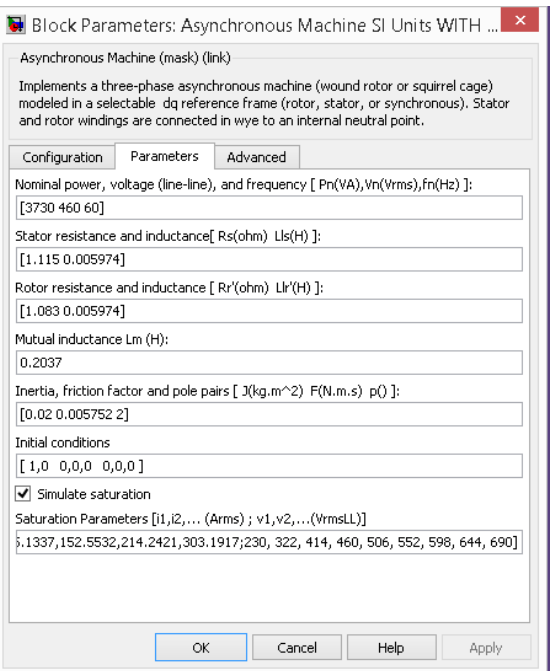

Fig. 4 Block parameters of saturated IM

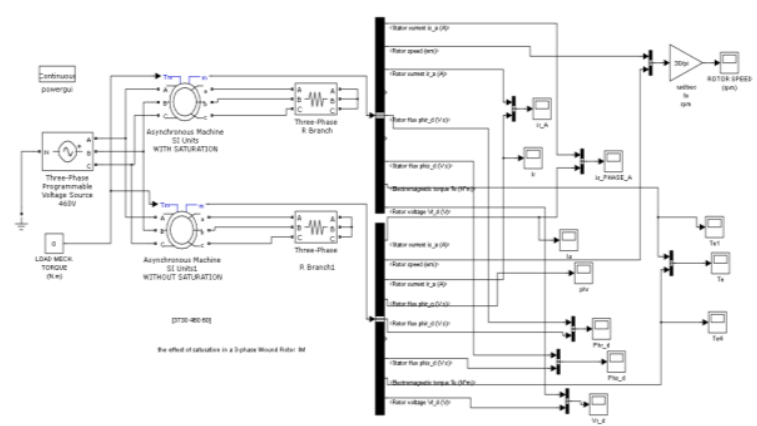

Fig. 5 The overall SIMULINK block diagram of the system

Referring to Fig.2 it can be seen that increasing the MMF (Ampere turns) in a magnetic circuit increases the flux machines are usually designed to work just below the onset of saturation. The simulation results were taken with three different cases; where the first case was taken with open loop external rotor resistance, the second case was taken with an external rotor resistance of $10 \mathrm{ohm}$ and the third case was taken with a short circuited external rotor resistance. However, the results illustrated in Figures (512) are with two different colours for the three cases. So that the results with blue line colours represent the saturated IM and that of green line colours are regarding the results of unsaturated IM. It is clear that there are big differences between all the results of the two machines for the three cases taken in this section. It is obvious that the results of the second machine (working under saturation condition) are affected by the nonlinear part due to the saturation, which is the nonlinear part of the B-H curve. This causes the nonlinear oscillation of the machine parameters, as shown in Figs 5-12.

\section{A. Case 1:}

The results of the IM with an open circuit external rotor resistance
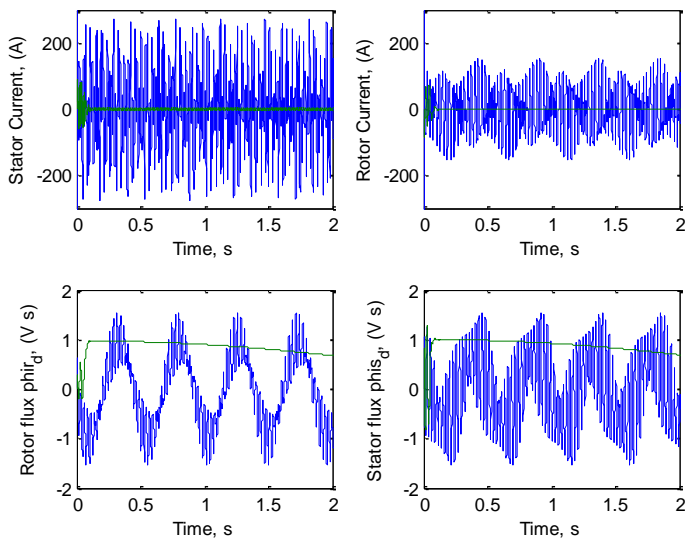

Fig. 5 the two machines time response of, stator current, rotor current, stator flux and rotor flux
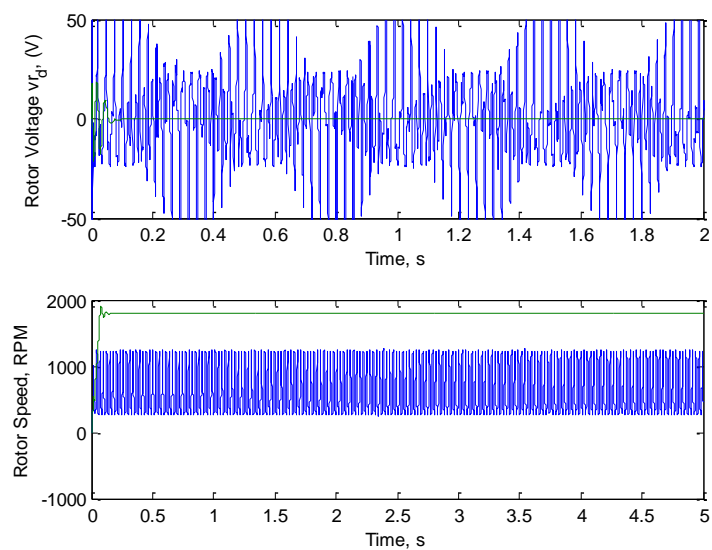

Fig. 6 the two machines time response of, rotor voltage and speed 
INTERNATIONAL JOURNAL OF INNOVATIVE RESEARCH IN ELECTRICAL, ELECTRONICS, INSTRUMENTATION AND CONTROL ENGINEERING Vol. 4, Issue 7, July 2016

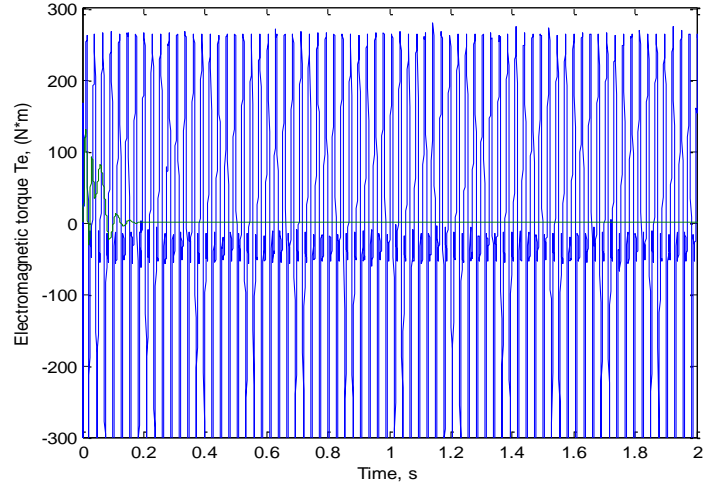

Fig. 7 the two machines time response of the electromagnetic Torque

B. Case 2:

The results of the IM with $10 \mathrm{ohm}$ external rotor resistance
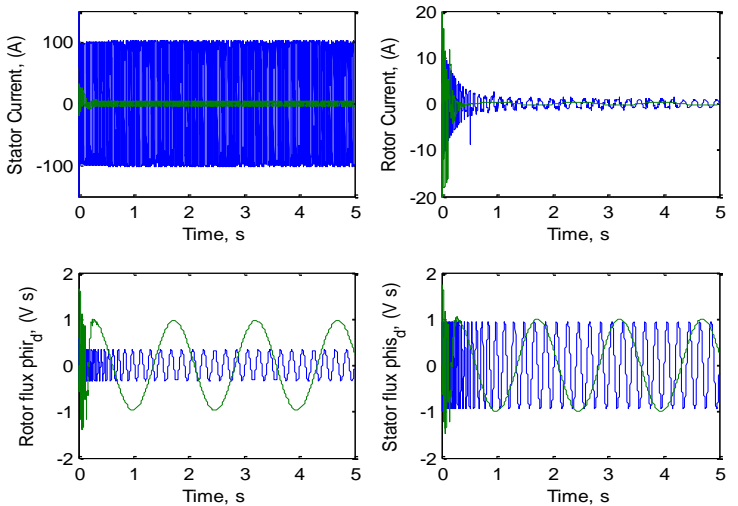

Fig. 8 the two machines time response of, stator current, rotor current, stator flux and rotor flux
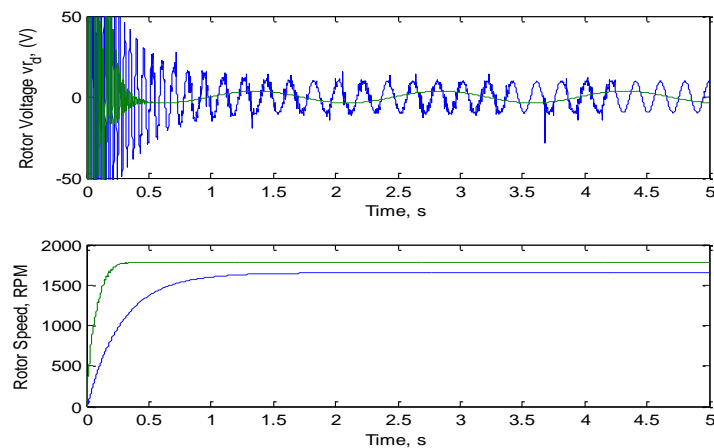

Fig. 9 the two machines time response of, rotor voltage and speed

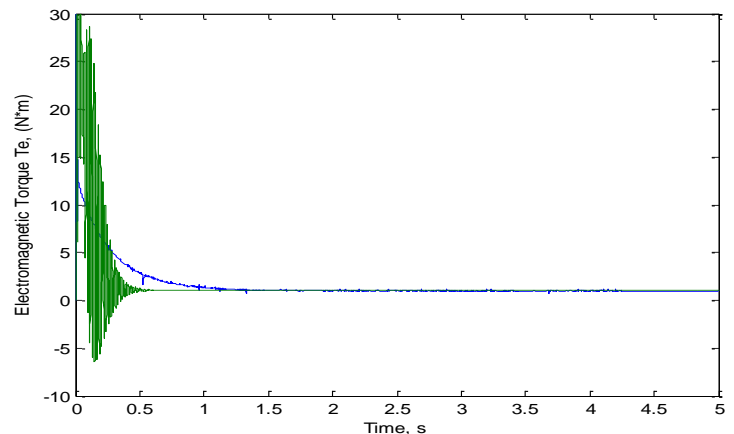

Fig. 10 the two machines time response of the electromagnetic Torque
C. Case 3:

The results of the IM with a short circuited external rotor resistance
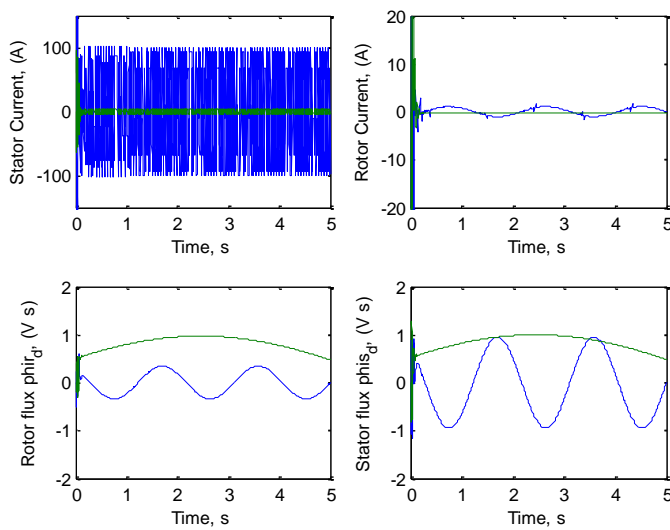

Fig. 11 the two machines time response of, stator current, rotor current, stator flux and rotor flux
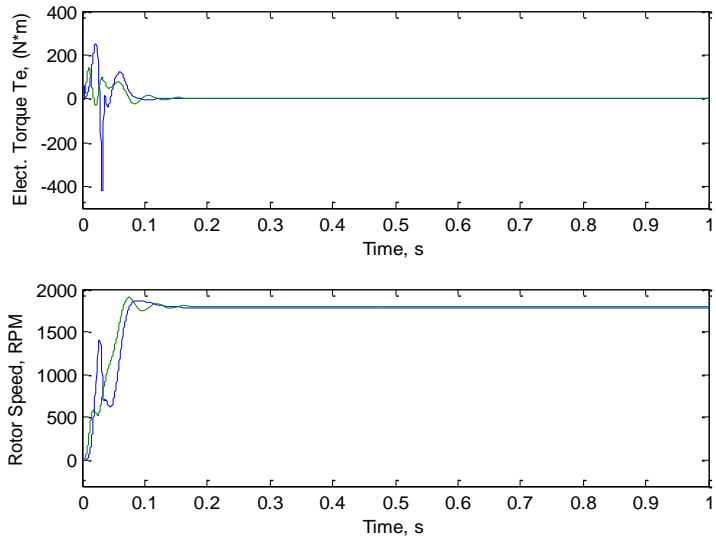

Fig. 12 the two machines time response of, electromagnetic Torque and rotor speed

\section{CONCLUSION}

The wound rotor induction motor offers a lot of flexibility for wide range of speed control compared to squirrel cage motor. The Simplest speed control scheme for woundrotor induction motors is achieved by changing the rotor resistance. An induction motor is more complicated than a transformer, however, because its leakage impedance may be affected by magnetic saturation of the leakage-flux paths and by rotor frequency. In this paper all cases were simulated and applied by using MATLAB/SIMULINK technique. The simulation results show the effect of saturation problem on the induction machine by comparing two identical machines working in different conditions. However the induction machines contain time varying coefficients, which describe the behaviour of induction machines and affect the machine analysis and performance. This is because the nonlinearity of the machine due to the saturation effect.

\section{ACKNOWLEDGMENT}

First of all, I would like to thank the government of Bahrain by the Higher Education Council for their 
continuous support of scientific research and to attain the Technology, Baghdad/Iraq, in 1995 and 2003, highest levels of the academic field. Furthermore, I would respectively.

like to thank the staff of Gulf University for unconditional I was shared and carried out many practical projects in support and understanding. Finally, my deepest gratitude different locations and companies in Iraq. These goes to my parents, wife and sons for their patience and encouragement.

\section{REFERENCES}

[1] Yuefeng Liao, And Thomas A. Lipo, "Effect Of Saturation Third Harmonic On The Performance Of Squirrel-Cage Induction Machines", Electric Machines \& Power Systems, Volume 22, Issue 2, 1994.

[2] Charles R. Sullvian, And Seth R. Sanders," Models For Induction Machines With Magnetic Saturation Of The Main Flux Path, IEEE Transactions On Industry Applications, Vol. 31, No. 4, Aug., 1995.

[3] Asmo Tenhunen, Timo P. Holopainen, And Antero Arkkio, "Effects Of Saturation On The Forces In Induction Motors With Whirling Cage Rotor", Reprinted From Proceedings Of Compumag'03, Vol. II. Saratoga Springs, NY, USA, 13-18 July 2003, Pages 66-67.

[4] T. Matsusaka, K. Harada, Y. Ishihara, T. Todaka, S. Kitamura, And T. Shimomura, "Analysis Of Characteristics Of Induction Motor By Three-Dimensional Axi-Symmetric Finite Element Method", 11th International Symposium On Electromagnetic Fields In Electrical Engineering (ISEF 2003), Maribor, Slovenia, September 18-20, 2003

[5] Darizon A. De Andrade, Marcos A. A. De Freitas, Luciano M. Neto, H'Elder De Paula, And Jos'E L. Domingos, "Effects Of Magnetic Saturation On Induction Machines Driven By Static Converters", Revista Controle \& Automatic, Vol.15 No.2/Abril, 2004.

[6] D. Dolinar, P. Lju`sev And G. `Stumberger, "Impact Of Magnetic Saturation On The Input-Output Linearizing Tracking Control Of An Induction Motor", Springer Recent Developments Of Electrical Drives, 247-260, 2006.

[7] J. Faiz And B. M. Ebrahimi, "Static Eccentricity Fault Diagnosis In An Accelerating No-Load Three-Phase Saturated Squirrel-Cage Induction Motor", Progress In Electromagnetics Research B, Vol. 10, 35-54, 2008, PP. 35-54

[8] F. Oliveira, M. P. Donsión, Jan Iwaszkiewicz, And Jacek Perz, "Operating An Electric Motor In Saturation - Mechanical Vibrations And Other Effects", International Conference On Renewable Energies And Power Quality (ICREPQ'10) Granada (Spain), 23rd To 25th March, 2010

[9] J. P. Lecointe, B. Cassoret, And J. F. Brudny, "Distinction Of Toothing And Saturation Effects On Magnetic Noise Of Induction Motors", Progress In Electromagnetics Research, Vol. 112, PP. 125-137, 2011.

[10] Dr. Ahmed Nasser B. Alsammak, And Mohammed Fawaz Thanoon, "An Improved Transient Model Of An Induction Motor Including Magnetizing And Leakage Inductances Saturated Effect”, International Journal Of Engineering And Innovative Technology (IJEIT), ISSN: 2277-3754, Volume 3, Issue 10, April 2014.

[11] Lakhya Jyoti Phukon, And Neelanjana Baruah, "A Generalized Matlab Simulink Model Of A Three Phase Induction Motor", International Journal Of Innovative Research In Science, Engineering And Technology (An ISO 3297: 2007 Certified Organization) Vol. 4, Issue 5, May 2015.

\section{BIOGRAPHY}

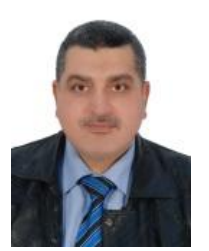

Dr. Osama Y. Mahmood Al-Rawi was born in Baghdad/Iraq, in 1967. I received the B. Sc. Degree in Electrical \& Electronics Engineering from the University of Technology, Baghdad, Iraq in 1989. I was one of the outstanding students; I take the second list of the graduated students in the Department of Electrical \& Electronics Engineering. The M.Sc. and Ph.D. degrees in Control System Engineering from the University of 